Original Research Article

\title{
Critical appraisal of Drug Promotional Literatures (DPLs) as per World Health Organization (WHO) guidelines
}

\author{
Pratit P. Vyas, Amol L. Bhave*
}

Department of Pharmacology, Medical College Baroda, Vadodara, Gujarat, India

Received: 14 December 2017 Accepted: 04 January 2018

*Correspondence to:

Dr. Amol L. Bhave,

Email: albhave2005@ rediffmail.com

Copyright: () the author(s), publisher and licensee Medip Academy. This is an openaccess article distributed under the terms of the Creative Commons Attribution NonCommercial License, which permits unrestricted noncommercial use, distribution, and reproduction in any medium, provided the original work is properly cited.

\begin{abstract}
Background: The study was aimed to critically analyse Drug Promotional Literatures (DPLs) using WHO guidelines. This would help to create awareness about DPLs amongst healthcare providers thus encouraging the improvement of healthcare system.

Methods: This cross sectional observational study was carried out at Department of Pharmacology, Medical College Baroda. DPLs were collected \& critically analysed for consistency, accuracy, validity of the provided information as per WHO guidelines.

Results: Out of total 616 DPLs collected, 371 satisfied the inclusion criteria. None of the DPL was fulfilling all criteria according to WHO guidelines. Most of DPLs were having information regarding; generic name / INN (98.39\%), brand name $(100 \%)$, amount of active ingredient per dosage $(94.07 \%)$, approved therapeutic uses (84.91\%), dosage form (91.37\%) and name \& address of manufacturers $(91.91 \%)$. Of all the DPLs, information provided for safety parameters like; name of active ingredient known to cause problem (11.59\%), dosage regimen $(32.88 \%)$, side effects \& drug reaction $(14.56 \%)$, major drug interactions (14.02\%) and precautions, contraindications and warning (14.29\%) seemed to be grossly neglected. Total of 431 claims were evaluated, of which the most common type of claim was efficacy (55.45\%). Relevant references to claims were present in (48.74\%) DPLs. Total 203 references were evaluated from 371 DPLs, of which maximum reference were from journal article $(74.38 \%)$.

Conclusions: From this study, it was concluded that pharmaceutical companies didn't follow the WHO guidelines for ethical drug promotion, thus failing to fulfil the rational promotion of drugs. Given the present findings physicians should be cautious about drawing conclusions regarding medicine based on DPLs provided by pharmaceutical companies.
\end{abstract}

Keywords: Drug promotional literatures, Drug marketing, Ethical drug promotion

\section{INTRODUCTION}

According to World Health Organization (WHO), Medicinal Drug Promotion refers to "all informational and persuasive activities by manufacturers and distributors, the effect of which is to induce the prescription, supply, purchase, and/or use of medicinal drugs". ${ }^{1}$
The main interest of pharmaceutical companies is to promote the sale of drugs, the primary goal being to convince physicians to prescribe the manufacturer's product through pharmaceutical advertisements. ${ }^{2}$ Pharmaceutical companies uses Direct-to-physician (DTP) technique as a major marketing strategy for the same. On the other hand, there are different modes of drug promotion including visual aids, flip charts, leave-behinds, advertisements, audio-visuals and gifts for the same., ${ }^{3,4}$ 
In India, promotional activities standards are set by selfregulatory code of pharmaceutical marketing practices, January and governed by Organization of Pharmaceutical Producers of India (OPPI), and by National legislation. ${ }^{5}$ However, many studies have revealed that the information/data provided through drug advertisements is inconsistent with the code of ethics.,6-8 It has been repeatedly shown by studies that physician's behavior is influenced by pharmaceutical promotions. ${ }^{4}$

Pharmaceutical industries by using promotional activities produces advertising brochures which at times are inaccurate and of poor educational value. ${ }^{9-11}$ These sort of promotional activities create the potential for inappropriate prescribing practices by influencing physicians' prescribing behavior without necessarily benefiting the patients. ${ }^{12-14}$ Majority of the health professionals are dependent on commercial sources of drug information from medical representatives, drug advertisement brochures etc., and it has great impact on prescribing behavior. ${ }^{15}$

Scientific data should be made available for the prescribers or any other person entitled to receive it on request, as appropriate to their requirement. ${ }^{1}$ Often the pharmaceutical companies claim that their new formulations are more superior to the existing ones. In addition, they also claim their products to be more effective and inexpensive as compared to the ones to which the prescribers and consumers are much more familiar. Though on many occasions, the materials provided through promotions are often misleading and confusing, but on the contrary doctors get motivated by the intensive marketing made by pharmaceutical companies that too without verifying whether the claims made are justified or not. ${ }^{9,15}$ The information provided in the promotional material may be inadequate or altogether inaccurate and when these are accepted without any query can lead to irrational prescribing.

WHO has published guidelines for ethical medicinal drug promotion in order to support and encourage the improvement in health care system through rational use of drugs and also has recommended for their implementation to its member states. These promotional activities highly influence the prescribing behavior of health care providers. In this era of growing popularity of evidence based medicine, it becomes utmost essential for critical analysis of drug promotional literatures to promote rational drug prescribing and patients compliance. ${ }^{10,16}$

\section{METHODS}

The design of this study was Cross sectional observation study.

\section{Data collection}

Size of the of the sample was Minimum 300 DPLs.

\section{Inclusion criteria}

All DPLs collected from-

- $\quad$ Pharmaceutical firms

- Medical representative association

- Private practitioners

- Multispecialty hospitals.

\section{Exclusion criteria}

- $\quad$ DPL for medicinal devices and equipment (insulin pump, blood glucometer, etc.)

- DPL for Homeopathic and Ayurvedic medicines

- Drug list

- Drug monographs

- Doubling of DPLs

\section{Methods of sample collection}

Following telephonic contact and conversation, details of our study were explained, and appointment timings were fixed for collection of DPLs.

DPLs collected from-

- Pharmaceuticals firms

- Medical representative association

- $\quad$ Private practitioners

- Multispecialty hospitals.

The same protocol was followed for all sectors during the period of data collection.

\section{Data analysis}

Data analysis was done under following headings:

\section{Fulfilment of WHO criteria}

Analysis of all the DPLs done according to ethical criteria for medicinal drug promotion by World Health Organization.

- $\quad$ The name(s) of the active ingredient(s) using either

- $\quad$ international non-proprietary names (INN) or the

- $\quad$ approved generic name of the drug

- The brand names

- Content of active ingredient(s) per dosage form or regimen

Name of other ingredients known to cause problems:

- $\quad$ Approved therapeutic uses

- Dosage form or regimen

- $\quad$ Side-effects and major adverse drug reactions

- Precautions, contra-indications and warnings

- Major interactions

- Name and address of manufacturer or distributor 
- Reference to scientific literature as appropriate

Claims

Claims made in DPLs were classified into following categories

\section{Efficacy}

Statements about improved effectiveness of promoted drug as a disease outcome or patient outcome solely in comparison with another group of drug with similar outcome.

- Safety: Use of word "safe" in promotional text or mentioning of reduction in adverse drug reaction and/or drug interaction and /or contraindication.

- Cost: Pointing out low price of promoted drug in absolute or relative terms or any description related to its better cost effectiveness.

- $\quad$ Pharmacokinetic property: Properties of drug related to its absorption, metabolism, half life etc.,

- $\quad$ Pharmacodynamic property: Properties related to its better mechanisms of actions.

- Pharmaceutical property: New drug formulations, different manufacturing procedures, excipients, storage facilities, etc.

\section{Retrievability and validity of references}

Promotional literatures quoting references in support of the claims made in it was further evaluated for its authenticity. References sustaining the claims were categorized as per the source of material, i.e. journals, websites, books, data on file, etc.

Further internet search was done to retrieve the references mentioned in DPLs. Authors have considered a reference as "available" if authors could retrieve a softcopy of the cited material in National Library of Medicine's, PUBMED or website of mentioned journal, freely in either full text or abstract format. References other than journal articles were searched through google search engine. As a corollary data on file, departmental studies and references not available from the search were considered nonretrievable. The available journal references were categorized as per type of study quoted in it or type of article as follows:

\section{Research article categorization}

- Randomized controlled trial

- Non-randomized controlled trial

- Randomized clinical comparison

- Randomized placebo controlled trial

- Case control study

- Case report

- In vitro study

- $\quad$ Prospective study
Data were entered using Microsoft Office Excel 2007. Descriptive statistics were produced for each outcome.

\section{RESULTS}

A total of 616 DPLs was collected, out of which 371 DPLs met the inclusion criteria

\section{Fulfillment of who criteria}

Most of DPLs were having information regarding; generic name / INN (365; 98.39\%), brand name (371; 100\%), amount of active ingredient per dosage (349; 94.07\%), approved therapeutic uses $(315 ; 84.91 \%)$ and dosage form $(339 ; 91.37 \%)$.

Of all the DPLs, information provided for safety parameters like; name of active ingredient known to cause problem $(43 ; 11.59 \%)$, dosage regimen $(122 ; 32.88 \%)$, side effects and drug reaction $(54 ; 14.56 \%)$, major drug interactions $(52 ; 14.02 \%)$ and precaution, contraindication and warning $(53 ; 14.29 \%)$ seemed to be grossly neglected. Moreover, this information were given in fine print and hard to read.

Majority of DPLs $(341 ; 91.91 \%)$ had mentioned the name and address of manufacturers. In addition to that we further evaluated the DPLs with name and address of manufacturers for availability of contact information for further correspondence and found that only 98 (28.74\%) of them had contact information like contact number, website, email id or fax mentioned (Table 1).

Table 1: WHO criteria $(n=371)$.

\begin{tabular}{|lll|}
\hline WHO criteria & $\begin{array}{l}\text { Complete } \\
\text { information } \\
\text { [No. of } \\
\text { DPLs (\%)] }\end{array}$ & $\begin{array}{l}\text { No } \\
\text { information } \\
\text { [No. of } \\
\text { DPLs (\%)] }\end{array}$ \\
\hline Generic name/INN & $365(98.39 \%)$ & $6(1.61 \%)$ \\
\hline Brand name & $371(100 \%)$ & $0(0 \%)$ \\
\hline $\begin{array}{l}\text { Amount of active } \\
\text { ingredient per dosage }\end{array}$ & $349(94.07 \%)$ & $22(5.93 \%)$ \\
\hline $\begin{array}{l}\text { Name of active } \\
\text { ingredient known to } \\
\text { cause problem }\end{array}$ & $43(11.59 \%)$ & $328(88.41 \%)$ \\
\hline $\begin{array}{l}\text { Approved therapeutic } \\
\text { uses }\end{array}$ & $315(84.91 \%)$ & $56(15.09 \%)$ \\
\hline Dosage form & $339(91.37 \%)$ & $32(8.63 \%)$ \\
\hline Dosage regimen & $122(32.88 \%)$ & $249(67.12 \%)$ \\
\hline $\begin{array}{l}\text { Side effects and drug } \\
\text { reaction }\end{array}$ & $54(14.56 \%)$ & $317(85.44 \%)$ \\
\hline $\begin{array}{l}\text { Major drug } \\
\text { interactions }\end{array}$ & $52(14.02 \%)$ & $319(85.98 \%)$ \\
\hline $\begin{array}{l}\text { Precautions, } \\
\text { contraindications and } \\
\text { warning }\end{array}$ & $53(14.29 \%)$ & $318(85.71 \%)$ \\
\hline $\begin{array}{l}\text { Name and address of } \\
\text { manufacturer }\end{array}$ & $341(91.91 \%)$ & $30(8.09 \%)$ \\
\hline
\end{tabular}




\section{Claims}

Authors have observed in our study that $91.37 \%$ of DPLs (339) were having one or more claims. Total of 431 claims were evaluated from 339 , of which the most common type of claim was efficacy $(239 ; 55.45 \%)$, followed by pharmaceutical property $(91 ; 21.12 \%)$, safety $(51$; $11.83 \%)$, pharmacokinetic property $(42 ; 9.74 \%)$, etc. (Figure 1).

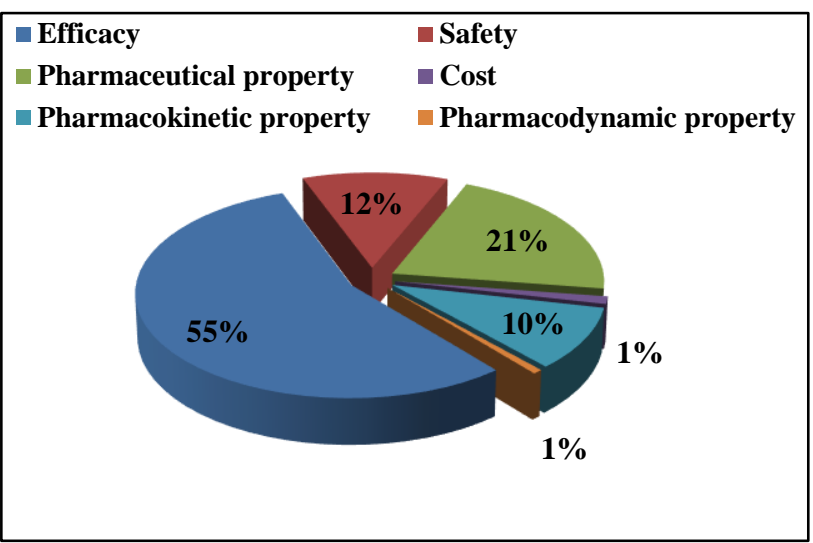

Figure 1: Type of claims $(n=431)$.

\section{Relevant references to claims}

It was observed in our study that DPLs with relevant references to claims were present in $181(48.74 \%)$ DPLs (Figure 2).

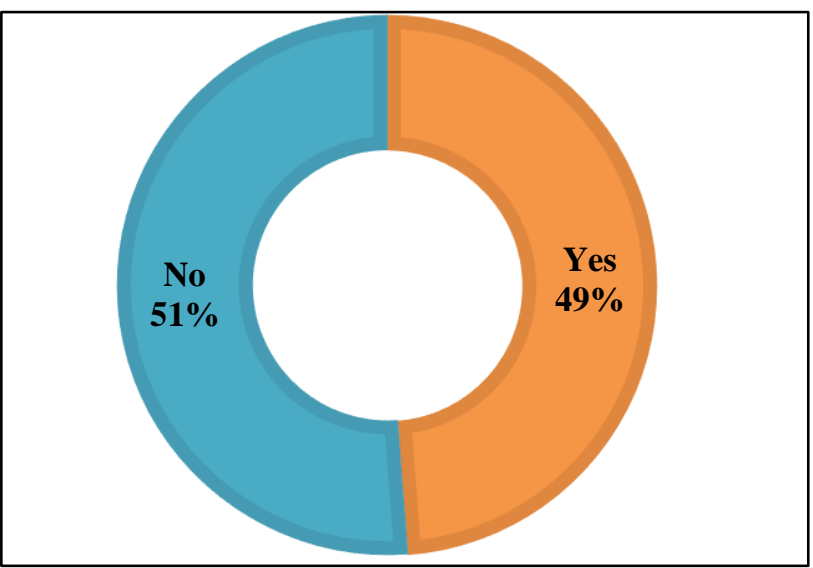

Figure 2: Relevant references to claims $(n=371)$.

\section{Retrievability and validity of references}

Total 203 references were evaluated from 371 DPLs, of which maximum reference were from journal article (151; $74.38 \%)$ followed by data on file $(21 ; 10.35 \%)$, websites $(16 ; 7.88 \%)$, books $(13 ; 6.4 \%)$, etc. (Figure 3$)$.

Of the total journal articles, maximum were research articles $(84 ; 55.63 \%)$ followed by review article $(55$;
$36.42 \%)$, editorial $(2 ; 1.22 \%)$ and not-retrievable (10; $6.63 \%$ ) (Figure 4).

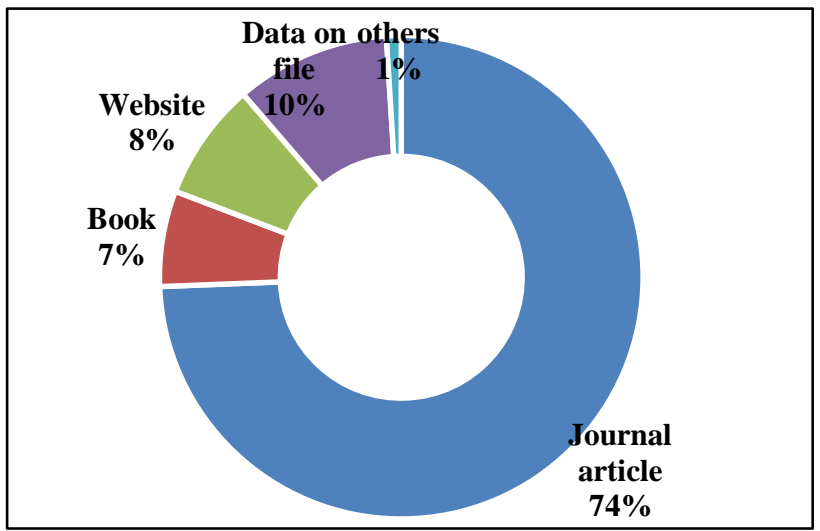

Figure 3: Sources of references $(n=203)$.

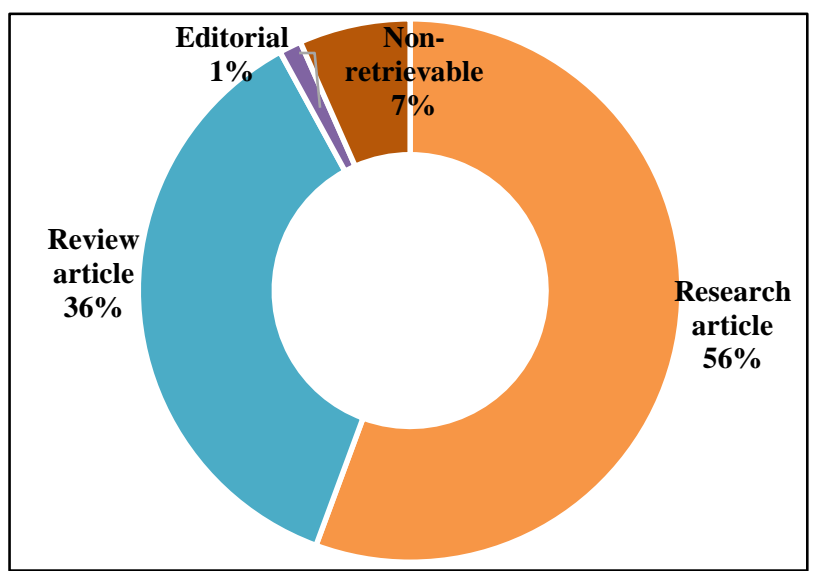

Figure 4: Evaluation of journal articles $(n=151)$.

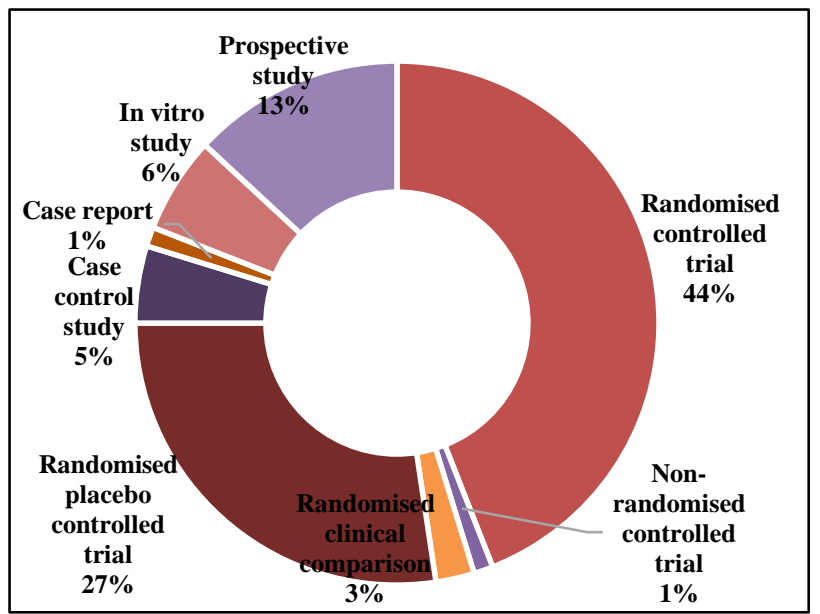

Figure 5: Evaluation of Research articles $(n=84)$.

Of the total research article evaluated, maximum was randomized control trial $(37 ; 44.05 \%)$ followed by randomized placebo controlled trial $(23 ; 27.38 \%)$, prospective study $(11 ; 13.1 \%)$, in vitro study $(1 ; 5.95 \%)$, etc. (Figure 5). 


\section{DISCUSSION}

Drug Promotional Literature (DPL) is readily available, easily accessible and important source of drug information. Direct-to-physician (DTP) marketing is one of the important facet of the promotion of pharmaceuticals. $^{4,10,17}$

WHO has published guidelines for ethical medicinal drug promotion in order to support and encourage the improvement in health care system through rational use of drugs and also has recommended for their implementation. Pharmaceutical industries do not follow WHO guidelines while promoting their drug products, thus accelerating their commercial motive rather than ethical educational aspect. As a result, little therapeutic information is provided to help physicians to reach any rational decision.

Although assessment of the truthfulness of the drug promotional claims is very complex, authors have tried to analyze this keeping in mind the objectives of the evidence-based medicine. Each DPL was analyzed objectively with the help of available evidences in the medical literature for its concurrence with WHO guidelines. A total of 616 DPLs was collected in our study, out of which 371 satisfied the inclusion criteria and rest 245 were excluded.

Provision of complete and balanced information about $\operatorname{drug}(\mathrm{s})$ is an essential element in drug promotion. Unfortunately, our study revealed that none of the DPLs were fulfilling all the criteria provided by WHO for ethical medicinal drug promotion. These findings have been also supported by other studies. ${ }^{2,18-20}$ From our study observations, they found that majority of literatures had mentioned generic name / INN (98.39\%), brand name (100\%), amount of active ingredient per dosage (94.07\%), approved therapeutic uses $(84.91 \%)$ and dosage form (91.37\%). These components being an essential part of detailed pharmacological information have been supported by Mali et al. and other studies. ${ }^{18-20}$

In all of the DPLs, information provided regarding safety parameters like; name of active ingredient known to cause problem $(11.59 \%)$, dosage regimen $(32.88 \%)$, side effects and drug reaction (14.56\%), major drug interactions $(14.02 \%)$ and precaution, contraindication and warning $(14.29 \%)$ seems to be too low and thus grossly neglected. These findings coincide with observations of another study conducted in Russia wherein safety parameters were mentioned in less than $5 \%$ of literatures. ${ }^{21}$ Another studies carried out in india by Mali et al. and others showed similar observations regarding safety information presented in DPLs. ${ }^{18-20}$ This suggests that unethical drug promotion especially in terms of neglecting the safety aspects of drugs is wide spread in india as well as all over the world, which truly demands utmost concern of health authorities. Moreover, this information was given in fine print which was not readily readable and the same is also supported by other study. ${ }^{22}$
Some studies. showed the presence of name and address of manufacturers in $71 \%$ and $52 \%$ of DPLs respectively. Another study by Jadav et al., showed the presence of name and address of manufacturers in $14.5 \%$ of DPLS only. Our study in contrast to above studies, revealed this very important information about name and address of manufacturers to be present in $91.91 \%$ of DPLs. Similarly in another study, also showed the presence of the same in $91 \%$ of DPLs. In addition to this, they further evaluated these DPLs having name and address of manufacturers, for contact information for further correspondence and found that only $28.74 \%$ of them had contact information like contact number, website, email id or fax, mentioned therein.

Of the total 431 claims evaluated, the most common type of claim found was about efficacy of an agent $(55.45 \%)$ followed by pharmaceutical property $(21.12 \%)$, safety $(11.83 \%)$, pharmacokinetic property $(9.74 \%)$, etc. Another study by Jadav et al. also observed that $45 \%$ of the DPLs were having efficacy as the most common type of claim. In contrast to above findings, it was observed in studies by Mali et al. and Villanueva et al. that $92 \%$ and $76 \%$ of DPLs were having efficacy as the most common type of claim provided. Practitioners and health professionals may be easily misguided by such catchy terms/phrases and unsubstantiated false claims. ${ }^{23}$

In contrast to the other studies in which DPLs with relevant references to claims were there in $67 \%$ and $71 \%$ of DPLs respectively, our study found it to be in $48.74 \%$ of DPLs only. Another study by showed that only in $35 \%$ of DPLs were having relevant references to claims. These findings underline the irresponsible behaviour and profit driven promotional attitude of the pharmaceutical industries, which is depriving the physicians of authentic drug information.

In our study, total of 203 references were evaluated. After classification of references, the most common reference quoted was from journal article $(74.38 \%)$ followed by data on file $(10.35 \%)$, websites $(7.88 \%)$, books $(6.4 \%)$, etc. Similar findings were also highlighted in other studies viz. in which journal article was the most common reference provided and it was mentioned in $84 \%, 63 \%, 88 \%$ and $55 \%$ of DPLs respectively. Out of total journal article references evaluated, maximum was research article $(55.63 \%)$ (including randomized control trial $(44.05 \%)$, randomized placebo controlled trial $(27.38 \%)$, prospective study $(13.1 \%)$, in vitro study $(5.95 \%)$, etc. followed by review article $(36.42 \%)$, editorial $(1.22 \%)$ and notretrievable $(6.63 \%)$. Similar findings were also consistent with findings of other studies. ${ }^{2,3,18,19}$

Printed promotional material is an important source of information. Most health professionals are dependent on commercial sources of drug information from medical representatives, drug advertisement brochures etc., and it has great impact on prescribing behaviour. ${ }^{15}$ On the basis of the observations of our study, it is suggested that 
physicians need to be aware of the flaws in promotional literatures before accepting it as valid source of drug information.

The strength of our study stands in the way of having critically evaluated drug promotional literatures which are the major source of establishing interaction between clinicians and manufacturers which in turn promote rational usage of various agents in order to better the health status of community.

authors do accept and feel that in this vast field of drug promotion strategies, also they have evaluated only one type of promotional activity, i.e. Drug Promotional Literatures (DPLs). Hence the need always stands to assess other forms of drug promotional activities also i.e. visual aids, leave behinds, leaflets and audio visuals.

\section{Funding: No funding sources}

Conflict of interest: None declared

Ethical approval: The study was approved by the Institutional Ethics Committee for Human Research (IECHR) Medical College and SSG Hospital, Baroda, Gujarat (Reg No: ECR/85/Inst/GJ/2013)

\section{REFERENCES}

1. Ethical criteria for medicinal drug promotion. World Health Organization [Online]. 1988 May 13. Available at: http://www.who.int/medicinedocs/collect/edmweb/pd f/whozip08e/ whozip08e.pdf.

2. Mali SN, Dudhgaonkar S, Bachewar NP. Evaluation of rationality of promotional drug literature using World Health Organization guidelines. Indian J Pharmacol. 2010;42:267-72.

3. Cooper RJ, Schriger DL. The availability of references and the sponsorship of original research cited in pharmaceutical 2005; 172:487-91

4. Cardarelli R, Licciardone JC, Taylor LG. A crosssectional evidence-based review of pharmaceutical promotional marketing brochures and their underling studies: Is what they tell us important and true? BMC Fam Pract. 2006;7:13.

5. OPPI code of pharmaceutical marketing practices. 2007. Available at: http://www.indiaoppi.com/OPPI\%20Code $\% 20$ of $\% 20$ Marketing\%202007.pdf [Online].

6. Stryer D, Bero LA. Characteristics of materials distributed by drug companies. An evaluation of appropriateness. J Gen Intern Med. 1996;11:575-83.

7. Smart S, Williams C. Evidence based advertising. Half of drug advertisements in BMJ over six months cited no supporting evidence? BMJ. 1997;315:1622-3.

8. Mindell J, Kemp T. Evidence based advertising. Only two fifth of advertisements cited published, peer reviewed references? BMJ. 1997;315:1622.
9. Rohra DK, Gilani AH, Memon IK, Perven G, Khan MT, Zafar H, et al. Critical evaluation of claims made by pharmaceutical companies in drug promotional material in Pakistan. J Pharm Pharm Sci. 2006;9:50-9.

10. Villanueva P, Peiro S, Librero J, Pereiro I. Accuracy of Pharmaceutical Advertisements in Medical Journals. Lancet. 2003;361:27-32.

11. Loke TW, Koh FC, Ward JE. Pharmaceutical advertisement claims in Australian medical publications: Is evidence accessible, compelling and communicated comprehensively? Med J. 2002;177(6).

12. Brody H. The company we keep: Why physicians should refuse to see pharmaceutical representatives. Ann Fam Med. 2005;3:82-5.

13. Orlowski JP, Wateska L. The effects of pharmaceutical firm enticements on physician prescribing patterns. There's no such thing as a free lunch. Chest. 1992;102:270-3.

14. Wazana A. Physicians and the pharmaceutical industry: Is a gift ever just a gift? JAMA. 2000;283:373-80.

15. Gopalakrishnan S, Murali R. India: Campaign to tackle unethical promotion. World Health Organization. Essential drugs monitor [Online] 2002:22. Available at: http://www.apps.who.int/medicinedocs/pdf/s4937e/s4 937e.pdf

16. Lexchin J. Enforcement of codes governing pharmaceutical promotion: What happens when companies breach advertising guidelines? CMAJ. 1997;156:351-6.

17. Medhi B, Prakash A. Ideal characteristics of promotional literature. In: Practical Manual of Experimental and Clinical Pharmacology. $1^{\text {st }}$ Edition. India: JBPMP. 2010:342-345.

18. Khakhkhar T, Mehta M, Shah R, Sharma D. Evaluation of drug promotional literatures using WHO guidelines. J Pharm Negative Results. 2013;4:33-8.

19. Jadav SS, Dumatar CB, Dikshit RK. Drug promotional literatures (DPLs) evaluation as per World Health Organization (WHO) criteria. J App Pharm Sci. 2014;4(06):084-8.

20. Alam K, Shah AK, Ojha P, Palaian S, Shankar PR. Evaluation of drug promotional materials in a hospital setting in Nepal. South Med Rev. 2009;2(1):2-6.

21. Vlassov V, Mansfield P, Lexchin J, Vlassova A. Do drug advertisements in Russian medical journals provide essential information for safe prescribing? West J Med. 2001;174:391-4.

22. Chakraborty A, Das SC. What not to do of drug promotion. 2005:16-3. Available at: http:// www.expresspharmaonline.com/ 20051130/ research02. html [Online].

23. Stimson GV. Information contained in drug advertisements. BMJ. 1975;4:508-9.

Cite this article as: Vyas PP, Bhave AL. Critical appraisal of Drug Promotional Literatures (DPLs) as per World Health Organization (WHO) guidelines. Int J Basic Clin Pharmacol 2018;7:238-43. 